\title{
ПРИЗНАКИ ИСКУССТВЕННОГО СТАРЕНИЯ И ВЛИЯНИЯ АГРЕССИВНЫХ ФАКТОРОВ НА ДОКУМЕНТ ПРИ УСТАНОВЛЕНИИ ВРЕМЕНИ НАНЕСЕНИЯ РЕКВИЗИТОВ
}

\author{
Крижановская Е.А., Тумоян Н.А., Гаврильченко Ю.В., Соломаха Ю.В. \\ Днепропетровский научно-исследовательский институт судебных \\ экспертиз Министерства юстиции Украины, \\ Днепр, Украина,
}

В статье рассмотрен актуальный вопрос установления абсолютного или относительного «возраста» документа или отдельных его частей (m. е. определение даты изготовления или последовательности выполнения текста). Часто на экспертизу предоставляют больщое количество таких поддельных документов, как договора, завещания, расписки, контракты, доверенности.

Поскольку бывают случаи, когда невозможно исследовать документ и установить сроки его выполнения, эксперту для установления относительного его “возраста» достаточно изучить: содержание и расположение отдельных частей; особенности знаков, текста (машинописного или типографрского); почерк, которым выполнена рукопись; состав и состояние итрихов и бумаги.

В статье описываются признаки и воздействующие факторы естественного старения документов, а также признаки и методы искусственного старения документов.

В практике судебных экспертов по техническому исследованию документов, неоднократно встречаются случаи исследования воздействия агрессивных факторов на документ. Раскрыты проблемные аспекты, возникающие у экспертов при проведении такого рода исследований.

В заключительной части статьи отмечается, что описанные примеры из экспертной практики и выявленные в процессе исследования признаки искусственного старения документа в своей совокупности устойчивые, существенные и индивидуальные, что приводит их к категорическим выводам.

Ключевые слова: искусственное старение, реквизиты, абсолютная давность, относительная давность, агрессивные фракторы, признаки искусственного старения.

На данный момент одним из важных вопросов и широко известных в технической экспертизе видов исследований документов является установление абсолютного или относительного «возраста» документа или отдельных его частей, т. е. определение даты изготовления или последовательности выполнения текста. Часто на экспертизу предоставляют большое количество таких поддельных документов, как договора, завещания, расписки, контракты, доверенности $[1,2]$.

Все чаще при проведении экспертиз по установлению абсолютного или относительного «возраста» документа или отдельных его частей реквизитов документов, эксперты сталкиваются

Адрес для корреспонденции: Крижановская Елена Анатольевна, судебный эксперт Днепропетровского научно-исследовательского института судебных экспертиз Министерства юстиции Украины, 49000, Украина, Сичеславская Набережная, 17, офис 801, г. Днепр, тел: (+38056)7785616, dniprondise@ukr.net. 
с фактами искусственного старение объектов исследования, а также влияния посторонних агрессивных фракторов на документы с целью невозможности проведения исследований по установлению времени нанесения реквизитов $[3,4]$.

Несмотря на стремительное развитие технологий и множество методик, встречаются случаи, когда невозможно исследовать документ и установить сроки его выполнения, однако для установления относительного его «возраста» бывает достаточно изучить: содержание и расположение отдельных частей; особенности знаков, текста (машинописного или типографрского); почерк, которым выполнена рукопись; состав и состояние штрихов и бумаги.

Устанавливая дату изготовления документа, необходимо точно знать условия его хранения. Поскольку методы ускоренного старения основаны на более интенсивном воздействии внешних факторов, признаки старости одинаковы и у документов с длительным сроком хранения, и у документов, подвергавшихся интенсивному воздействию внешних фракторов, т. е. в них происходят одинаковые фризико-химические изменения материалов письма. Кроме того, в различные промежутки времени документы могут находиться в условиях, способствующих их сохранению, и в условиях, ускоряющих процессы старения. Разумеется, определить в таких случаях интенсивность воздействия внешних факторов, а следовательно, и время составления документа невозможно.

В практике судебных экспертов по техническому исследованию документов, неоднократно встречаются случаи исследования воздействия агрессивных фракторов на документ.

Воздействие агрессивных факторов на документы приводит к несоответствию компонентного состава реквизитов документов реальному времени их составления, и, как следствие, усложняет, а в некоторых случаях, делает невозможным установление давности нанесения этих реквизитов.

Старение документа - это непрерывный процесс, который происходит естественно (природное старение), либо искусственно (ускоренное старение). При любом старении меняется качественный и количественный состав материалов письма, морфологические, а в некоторых случаях и фризико-химические характеристики. Природное старение документа происходит медленно под воздействием внутренних и внешних факторов. Искусственное же старение происходит быстро и чаще всего применяется в случаях попытки фральсификации документов. Такое старение применяется в качестве противоправных действий. Целью состаривания документов различными способами является видоизменение документа не позволяющее экспертам устанавливать действительную дату создания документа.

Следовательно, искусственное старение - это результат воздействия посторонних фракторов, которые не соответствуют обычным условиям хранения документов, что проявляется в несоответствии компонентного состава реквизитов документов реальному времени их выполнения.

Основными факторами и причинами разрушения документов являются:

- свет - самый опасный и быстродействующий фрактор;

- температура - активирует все химические реакции старения;

- влажность воздуха - изменяет пористость бумаги;

- сам материал документа - является внутренним фрактором (имеется в виду, что состав бумаги может отличаться, и различные компоненты по-разному себя ведут при хранении).

- остальные фракторы (механические повреждения, экология среды, резкая смена климата, биологические вредители, такие как грибок и насекомые).

Таким образом, если при проведении предварительного изучения документа для установления его пригодности с целью проведения исследований по установлению абсолютного времени 
выполнения реквизитов иногда выясняется, что указанные в нем фракты не могли произойти в то время, которым он датирован, необходимо провести комплексные экспертные исследования.

Например, исследование почерка и особенностей письменных знаков иногда также помогает устанавливать время составления документа. При этом можно выявить приписки, сделанные другим лицом, что в совокупности с другими признаками может свидетельствовать о неодновременности исполнения различных частей текста. Если дописка сделана тем же человеком, который ранее составлял документ, то можно определить различия в признаках почерка, поскольку устойчивость почерка не абсолютна, а относительна. Кроме того, внося в документ изменения, преступник стремится воспользоваться таким же материалом, каким был написан первоначальный текст, однако подбирает его визуально, «на глаз», и он оказывается сходным только по виду, но не по составу. Дописку можно выявить также по различию структуры штрихов, обусловленному рельефными особенностями поверхности, на которой лежал документ в момент выполнения записей [5].

В целом при исследовании воздействия агрессивных факторов на документ эксперт руководствуется традиционной методикой исследования с учетом специфических признаков, которые несвойственны естественному хранению:

- признаки, которые возможно определить визуально при осмотре документа и при помощи специального оборудования без повреждений;

- признаки, которые определяются фризико-химическими методами исследования.

В экспертной практике чаще всего встречаются следующие признаки искусственного старение:

1. На бумаге:

- неравномерный цвет: может меняться от желтого до коричневого, а также может быть разным с одной и с другой стороны листа (со стороны воздействия стать желтым, а с другой - оставаться белым);

- рыхлость, шероховатость, или же наоборот, повышенный глянец поверхности;

- деформация бумаги: заломы и складки;

- необычный «хруст» бумаги;

- пятна и наслоения посторонних веществ, которые не имеют отношения к материалам реквизитов документа;

- различная интенсивность люминесценции участков бумаги в УФ зоне спектра.

2. В записях и подписях, выполненных пастами шариковых ручек:

- расплывы красящего вещества в штрихах, в том числе пропитка в направлении обратной стороны листа;

- потеря блеска красящих веществ, потеря цвета;

- неравномерный цвет штрихов, резкий переход между сильно и слабо окрашенными участками;

- проявление серых, серо-зеленых оттенков для паст синих и сине-фриолетовых оттенков и для черных - серо-фиолетовых оттенков;

- проявление желтоватого окраса по краям штрихов;

- изменение в микроструктуре штрихов, например рыхлость красящего вещества вследствие запекания;

- неравномерная люминесценция штрихов. 
Экспериментальным путем установлено, что воздействие на документ одновременно трех факторов: света, температуры и влажности, значительно ускоряет изменение физико-химических свойств материалов документа.

Подробнее остановившись на температурном влиянии можно выделить следующие методы старение:

1. Низкотемпературное - это когда документы состаривают например на радиаторах отопления, в термошкафах, на электрических плитах, либо же обдувают теплым воздухом при помощи фена. В таких случаях данное термическое влияние сложно выявить визуально. И только лишь при использовании фризико-химических методов исследования, возможно, зафиксировать изменения в реквизитах документов.

Одними из таких признаков являются:

- складки, заломы либо же повышенная шероховатость бумаги;

- расплывы (за пределы штрихов) на записях и подписях документа красящих веществ и их частичное отображение на обратной стороне листа;

- проявление блеклости в штрихах шариковых ручек при низкотемпературном воздействии, а также наличие сероватого оттенка цвета красящего вещества;

- частички тонера в красящем веществе могут отслаиваться, что видно визуально.

2. Высокотемпературное - это когда документ пытаются состарить при помощи нагретых до высокой температуры предметов. Например, при помощи утюга или утюжок для волос.

Перечисленные признаки определяются легко по причине изменения морфологической структуры поверхности бумаги и штрихов реквизитов документа:

- в местах взаимодействия нагретых предметов с поверхностью документа будет наблюдаться зеркальный блеск;

- на бумаге могут присутствовать посторонние вещества, к примеру, остатки загрязнений с контактирующей поверхности;

- штрихи тонера превращаются в однородную расплавленную массу, и невозможно рассмотреть мелкозернистую структуру;

- красящее вещество тонера печатного текста смазывается и растекается;

- сами волокна бумаги также изменяют цвет, при этом наблюдаются волокна с цветом от желтого до темно-коричневого оттенка.

Также часто встречаются случаи старение документа путем многократного прогона листа через узел тонера копировальных устройств, так как там также документ поддается высокотемпературному влиянию.

В аналогичных случаях признаки определяются следующим образом:

- на поверхности бумаги наблюдаются многочисленные частички тонера, количество и плотность размещения которых нехарактерны для одноразового пропускания листа через принтер;

- штрихи теряют глянец, а частички тонера осыпаются [6].

Ниже на примере из экспертной практики авторов опишем случай, когда одним из сорормулированных вопросов был «Выполнен рукописный текст заявления об увольнении и дата в один или разные периоды времени?». В ходе исследования были выявлены слабовидимые (обесцвеченные) записи в левом углу в заявлении об увольнении. Дальнейшим исследованием было выявлено признаки, которые указывали на травление этих записей, смывание и 
термическое влияние на бумагу и на штрихи рукописного текста расписки:

- бумага рыхлая и шершавая на ощупь, на ней наблюдается большое количество морщин, помятость листа;

- выявлены нарушения проклейки бумаги: хрупкость, ломкость, шероховатость, потеря глянца, различия в цвете. С лицевой стороны лист желтоватого цвета, а с обратной стороны белый, по краям лицевой стороны листа имеются расплывы желтого цвета;

- на некоторых участках бумаги имеются остатки темно-бурого маслянистого вещества;

- в верхнем правом углу были обнаружены слабовидимые (обесцвеченные) штрихи светло - коричневого цвета, которые люминесцируют в видимой люминесценции в красной зоне спектра, возбужденного сине-зелеными «Освободить от должности тренера преподавателя отделения футбола .... года, с отработкой двух недель. Подпись»;

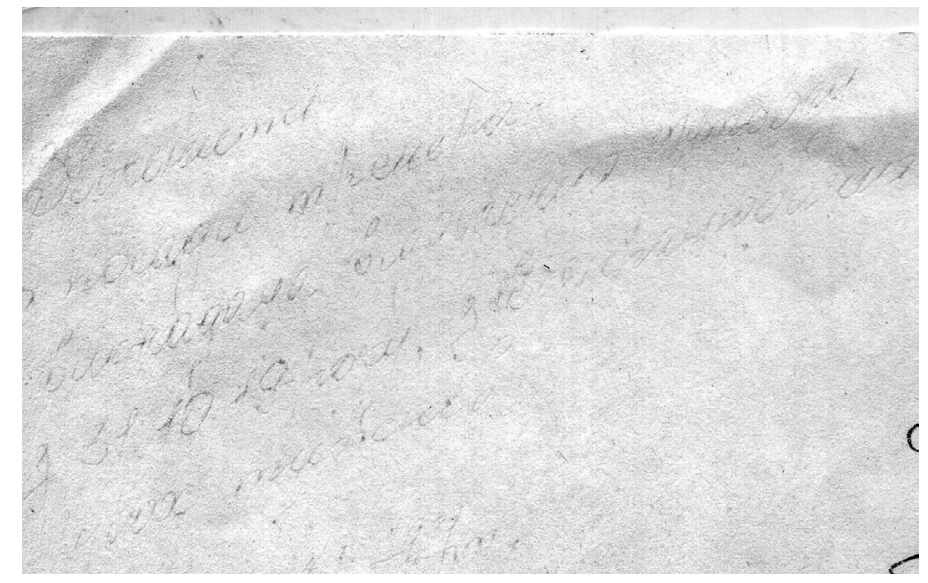

Рис. 1. Слабовидимые (обесцвеченные) итрихи светло - коричневого цвета на заявлении в левом верхнем углу

- наличие люминесцирующих пятен, вертикальных коричневых полос по всей площади бумаги при воздействии УФ - лучей;

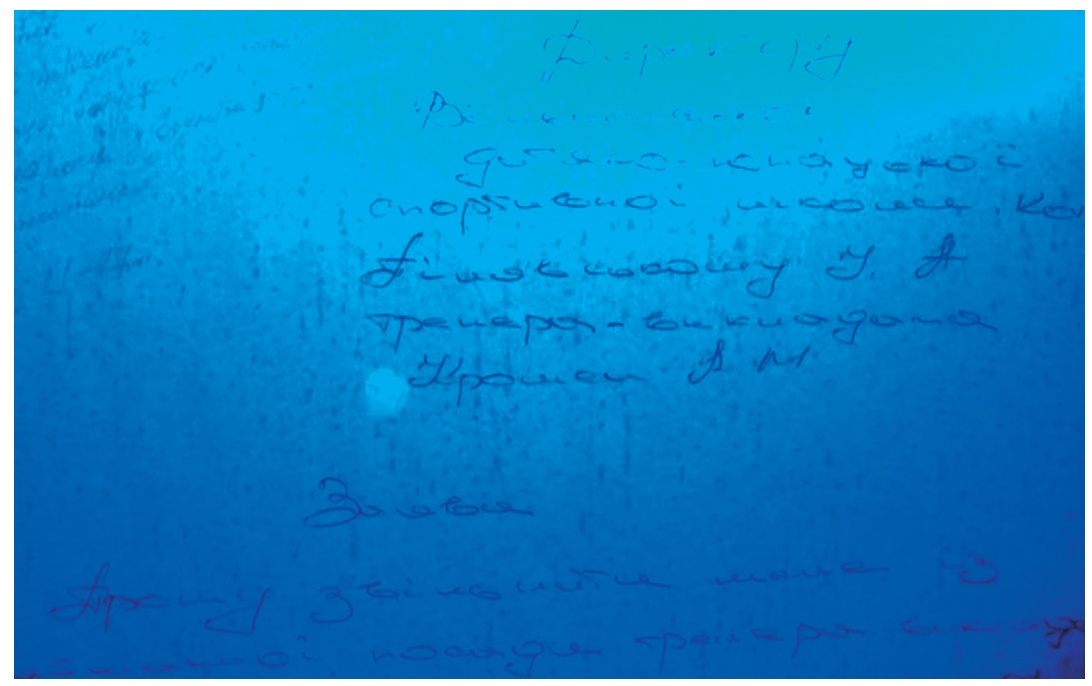

Рис. 2. Люминесцирующие пятна и вертикальные коричневые полосы по всей площади бумаги при воздействии УФ - лучей 
- в слое бумаги наблюдаются волокна желто-коричневого цвета;

- наблюдается изменение насыщенности, и цвета штрихов в верхней части, и все штрихи имеют нехарактерный для паст шариковых ручек серо-зеленый оттенок.

Следовательно обнаружены признаки, которые свидетельствуют о том, что в заявление вносились изменения путем травления рукописных записей в верхнем левом углу «Освободить от должности тренера - преподавателя отделения фрутбола .... года, с отработкой двух недель. подпись», затем смыва химических веществ и сушки заявления с применением термического влияния на него. Таким образом, на документ осуществлялось влияние агрессивных фракторов, не свойственных для обычных условий хранения документа.

Дальнейшим изучением штрихов основного текста заявления и даты было выявлено следующее:

- одинаковый серо-синий оттенок пасты для шариковых ручек;

- одинаковое неравномерное распределение красителя в виде многочисленных трасс, индивидуализирующих десект пишущего прибора;

- одинаковая отражающая способность штрихов;

- одинаковая ширина штрихов 0,3 мм.

Но наряду с этим, при разной направленности света, изучением рельефа и высоты (глубины) штрихов рукописного текста и даты на лицевой и обратной стороне листа заявления было установлено:

- разный наклон продольных осей прямолинейных элементов основных рукописных записей и даты;

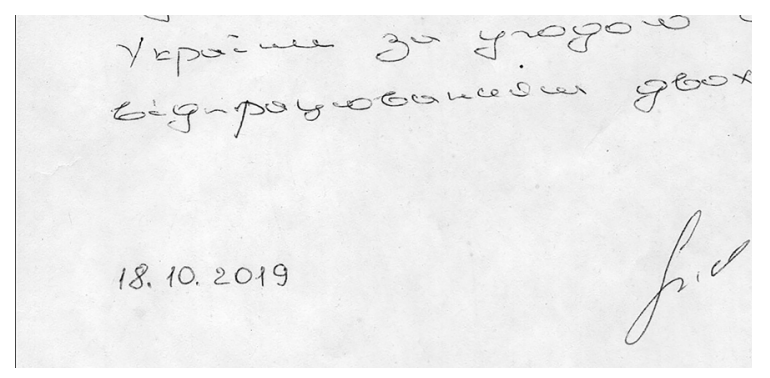

Рис. 3. Серо-зеленый оттенок штрихов рукописных записей и даты, а так же разный наклон продольных осей прямолинейных элементов основных рукописных записей и даты

- разная сила нажима при выполнении рукописного текста заявления и даты, характеризуется разной глубиной рельефа вдавленных штрихов даты по отношению к основному рукописному тексту на лицевой стороне;

- неодинаковая сила нажима при письме или различные виды подложки, на которых выполнялись рукописные записи, характеризуется разной высотой рельефа выпуклых штрихов даты, по отношению к основному рукописному тексту на обратной стороне листа. 


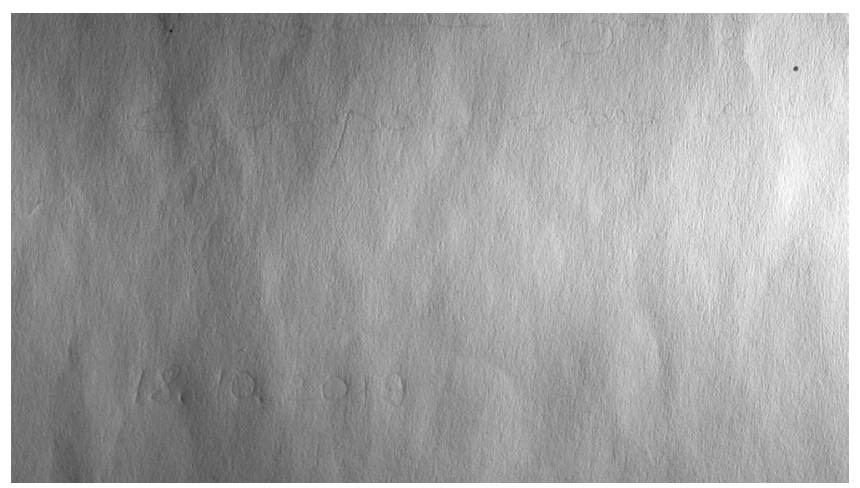

Рис. 4. Разная высота рельефа выпуклых итрихов даты, по отношению к основному рукописному тексту на обратной стороне листа в ИК лучах и косо падающем свете

Обнаруженные признаки в своей совокупности устойчивые, существенные, индивидуальны, что дает основание сделать категорический вывод о том, что в заявление вносились изменения путем вписывания даты, то есть дата была дописана.

Почерковедом исследовались рукописные записи основного текста заявления и даты, результатом исследования было установлено, что основные рукописные записи выполнены лицом, от имени которого написано заявление, а дата выполнена другим лицом. Следовательно, вывод эксперта о дописке даты подтвердился, то есть вышеперечисленные факторы дают основание сделать категорический вывод о том, что основной рукописный текст и дата были выполнены в разные периоды времени.

Вышеприведенные примеры показывают, что для определения относительного «возраста» документа достаточно исследовать все факторы, влияющие на документ и выполнение реквизитов, а также обнаружить фракты, которые не могли произойти в то время, которым датирован документ. В данном случае были использованы методы, которые не привели к повреждению исследуемого документа, что позволило не применять физико-химические методы, а так же и дорогостоящего оборудования.

\section{Список литературы}

1. Цимбал А.В. «Ключевые аспекты методических подходов при установлении абсолютного времени выполнения реквизитов документов с использованием газохромотологического метода исследования». Криминалистика и судебная экспертиза: Междуведомственный научно-методический сборник. Вып. 58, ч. 1/ Отв. ред. И.И. Емельянова. - К. Министерство юстиции Украины, 2013.

2. Веневцев А.Н. «К вопросу о моделировании процессов старения штрихов реквизитов документов с целью установления абсолютной давности их выполнения». Международный журнал прикладных и фундаментальных исследований, № 8, 2015.

3. Гаджикурбанов Б.А. «Искусственное старение документов как один из способов подделки документов: методы пресечения». Журнал Бизнес в законе Издательство: Издательский дом «ЮрBAK», 2009.

4. Иванов Н.А. «Естественное и искусственное старение документов». Издание Эксперт криминалист № 3, 2013.

5. Аксенова В.В. «Технико-криминалистическое исследование документов, подвергшихся естест- 
венному изменению». К. Министерство юстиции Украины, 1972.

6. Посольский О.О. «Вдосконалення методики встановлення змін хімічного складу барвних речовин у часі». Методика разработанная Киевским научно - исследовательским институтом судебных экспертиз Министерства юстиции Украины.

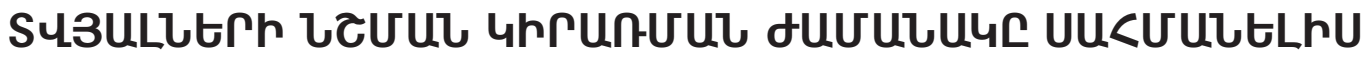

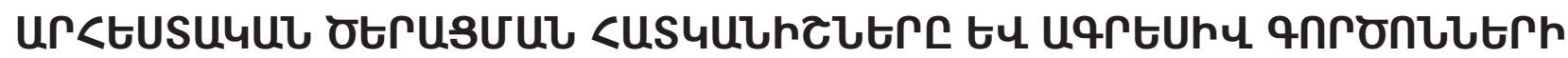

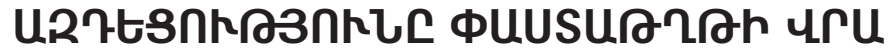

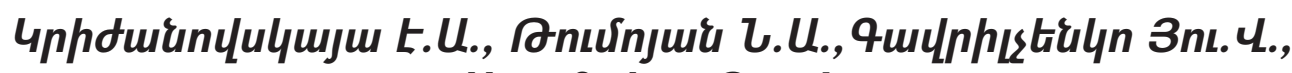 Un!nviupuu 3nı. 4.}

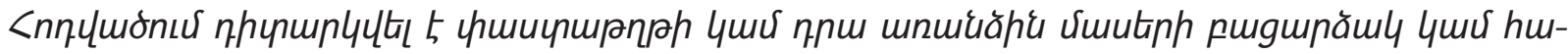

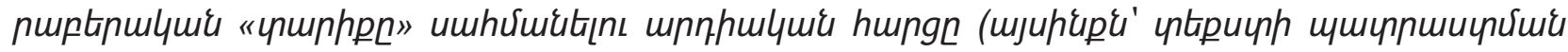

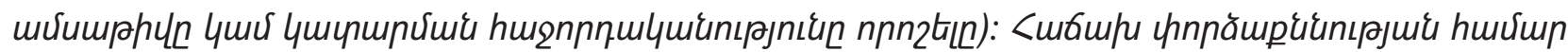

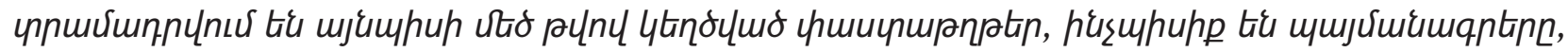

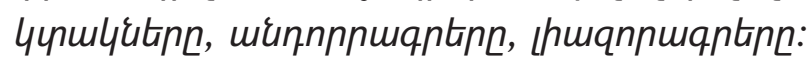

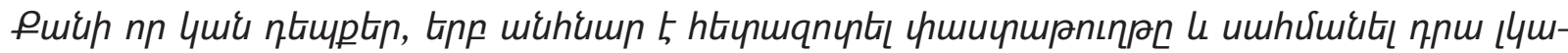

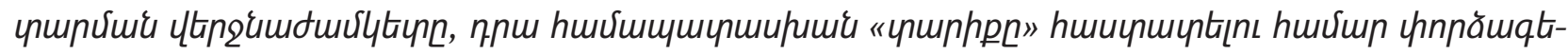

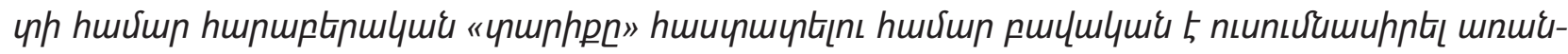

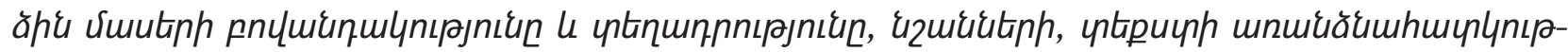

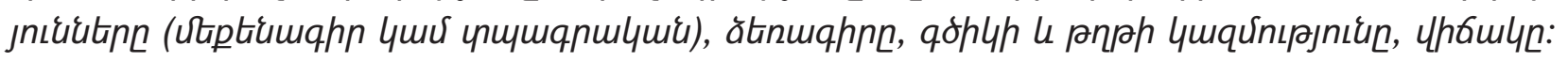

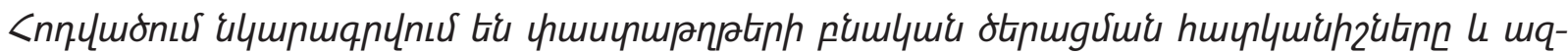

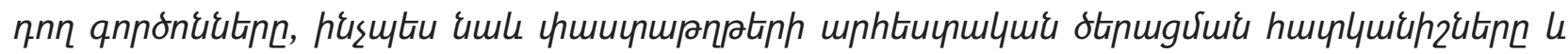
utipnnutinn:

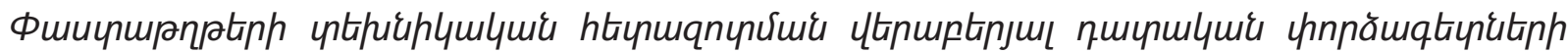

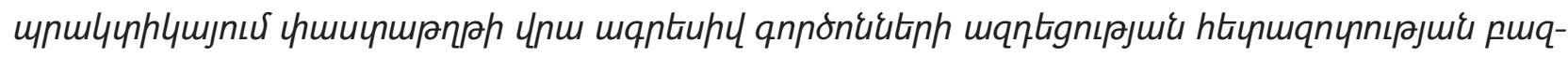

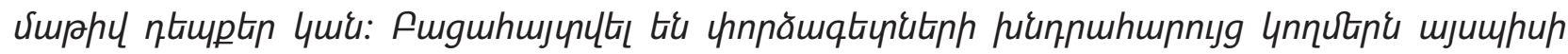

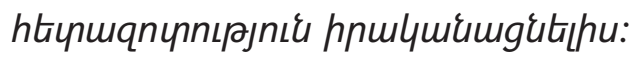

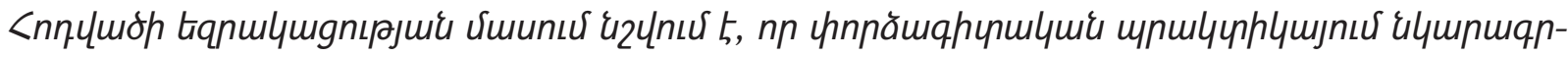

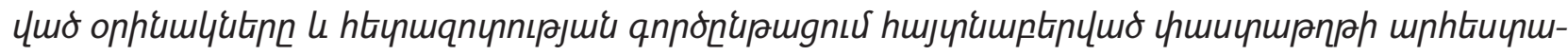

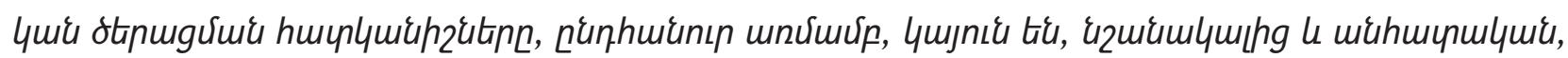

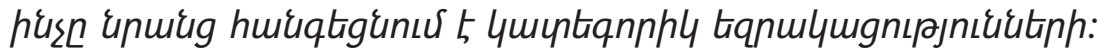

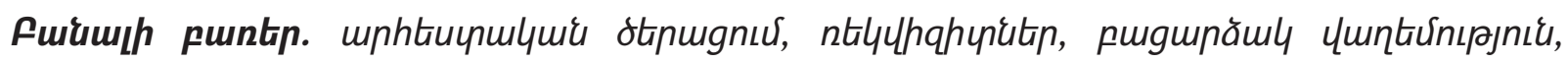

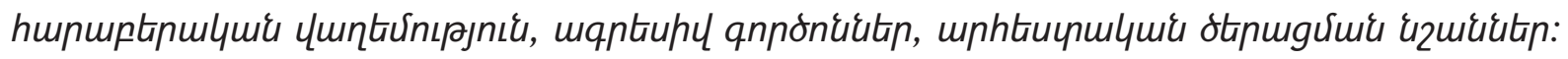

\section{SIGNS OF ARTIFICIAL AGING AND INFLUENCE OF AGGRESSIVE FACTORS ON THE DOCUMENT WHEN ESTABLISHING THE TIME FOR APPLICATION OF DATAS}

\section{Krizhanovskaya E., Tumoyan N., Gavrilchenko J., Solomakha J.}

The article discusses the topical issue of establishing the absolute or relative "age" of a document 
or its individual parts (i.e. determining the date of manufacture or the sequence of execution of the text). Often a large number of such forged documents as contracts, wills, receipts, contracts, powers of attorney are provided for a forensic examination.

Since there are cases when it is impossible to study a document and set a deadline for its completion, in order to establish its relative "age" it is enough for an expert to study: the content and location of individual parts; features of signs, text (typewritten or typographic); handwriting of the manuscript; composition and condition of smears and paper.

The article describes the signs and factors of influence of natural aging of documents, as well as signs and methods of artificial aging of documents.

In the practice of forensic experts on the technical study of documents, there are numerous cases of researching the impact of aggressive factors on a document. The problematic aspects of specialists in conducting this kind of research have been identified.

As a result, the authors arrive at the conclusion that the examples from expert practice described in the article and the signs of artificial aging of the document identified in the research process are, in their totality, stable, significant and individual, which leads them to categorical conclusions without the involvement of specialists in the study of document materials.

Key words: artificial aging, requisites, absolute prescription, relative prescription, aggressive factors, signs of artificial aging.

Статья поступила: 05.05.2021

Принята к печати: 08.05.2021 